\title{
Acidentes com materiais perfurocortantes e o profissional de enfermagem
}

Claudio Vieira de LIMA $^{1}$

Deivison R. PINTO

Maria Alzira RAMOS ${ }^{3}$

\author{
${ }^{1}$ Psicólogo, mestre em Bioética, especialista em Docência do Ensino Superior, Especialista em Psicologia Médica, \\ professor titular da UNINCOR-Betim \\ ${ }^{2}$ Enfermeiro da Prefeitura de Belo Horizonte - SAMU \\ ${ }^{3}$ Enfermeira da Prefeitura de Belo Horizonte - Hospital Odilon Berhens
}

Autor correspondente:

Claudio Vieira de Lima

Rua Capri, 70 Bairro Arquipelogo Verde Betim (MG)

claudiolimas@yahoo.com.br

Recebido em: 12/07/2012 - Aprovado em: 22/12/2012 - Disponibilizado em: 30/12/2012

\section{RESUMO:}

Este estudo constitui-se em uma revisão integrativa da literatura que teve como objetivo identificar a ocorrência de acidentes com materiais perfurocortantes entre os profissionais de enfermagem e como a equipe de enfermagem pode atuar na prevenção destes acidentes. O acidente de trabalho é aquele que advém do exercício do trabalho provocando lesão corporal e até a morte, perda ou diminuição (transitória ou permanente) da capacidade funcional. Foram realizados busca nos bancos de dados: Base de Dados de Enfermagem, Biblioteca Virtual em Saúde, Biblioteca Regional de Medicina, Literatura Latino-Americana e do Caribe em Ciências da Saúde, Literatura Internacional em Ciências da Saúde, Scientific Eletronic Library Online, Manuais do Ministério da Saúde e Secretarias Estaduais e Municipais de Saúde e Revistas Eletrônicas, no período de 2000 a 2011 e a população do estudo foi toda a literatura indexada nos bancos de dados selecionados. A amostra foi realizada a partir da análise crítica da literatura e foi constituída por 09 artigos. A partir da leitura e análise dos artigos, foi constatado que os acidentes com materiais perfurocortantes ocorrem com maior intensidade com as categorias de auxiliares de enfermagem. Os autores também afirmam que há necessidade de intervenções por parte dos enfermeiros e dos trabalhadores que contemplam a organização/reorganização de trabalho no que diz respeito a medidas preventivas e programas de educação continuada. Então, é importante que abordem nos hospitais mais a questão dos acidentes de trabalho e a exposição aos materiais perfurocortantes, esclarecendo bem aos profissionais de enfermagem sobre a importância de se notificar o ocorrido, a busca pelo atendimento médico nos primeiros momentos que seguem o acidente, sensibilizá-los quanto à utilização correta dos EPI e a precauções padrão.

Palavras-Chave: Acidentes de trabalho. Material biológico. Enfermagem, perfurocortante.

\section{Accidents with sharps and professional nursing}

\begin{abstract}
:
This study is in an integrative literature review aimed to identify the occurrence of accidents with needlestick materials among professionals such as nurses and nursing staff can act to prevent these accidents. The accident at work is that which comes from the performance of work causing injury and even death, loss or reduction (transient or permanent) functional capacit. We conducted searches in databases: Database of Nursing, Virtual Health Library, Regional Library of Medicine, the Latin American and Caribbean Health Sciences Literature International Health Sciences, Scientific Electronic Library Online Manuals Ministry of Health and State and Municipal Health and e-magazines in the period 2000 to 2011 and the study population was all the literature indexed in selected databases. The sample was made from the analysis of literature and consisted of 09 items. From reading the articles and analysis, it was found that accidents with sharps occur with greater intensity to the categories of nursing assistants. The authors also claim that there is need
\end{abstract}


for interventions by nurses and workers who comprise the organization / reorganization of work in relation to preventive measures and continuing education programs. So it's important to address in hospitals over the issue of workplace accidents and exposure to sharps, accounting and nursing professionals on the importance of notifying the incident, the search for medical care in the first moments following the accident, raising awareness them on the correct use of PPE and standard precautions.

Keywords: Accidents at work. Biological material. Nursing.

\section{INTRODUÇÃ̃o}

O trabalho por ser uma atividade social, tem importante função nas condições de vida do ser humano, pois produz um efeito positivo quando satisfaz as necessidades básicas de subsistência, criação e colaboração dos trabalhadores. Em contrapartida, ao realizá-lo o homem expõe-se constantemente aos riscos presentes no ambiente laboral, os quais podem interferir em sua condição de saúde (CANINI et al. 2002).

Estas ocorrências são caracterizadas como acidentes de trabalho que se refere a lesões decorrentes de traumas, fatores externos e envenenamentos ocorridos no ambiente do trabalho durante a execução de atividades e/ou durante o trajeto ao trabalho de ida ou volta, e às doenças ocupacionais (SANTANA et al. 2006).

Com intuito de minimizar os riscos aos quais os trabalhadores da área de saúde estão expostos, a Lei Federal 6514 de 22/12/1977 (alterou o capitulo V, do titulo II da Consolidação das Leis do Trabalho) aprovou todas as normas regulamentadoras (NR), sendo que, em 6/12/2002 a Portaria
N. 37 divulgou a NR 32 que está ligada diretamente a Segurança e Medicina do Trabalho. O quadro III desta NR refere-se aos materiais perfurocortantes, no qual estabelece diretrizes para elaboração e implementação de medidas de prevenção, promoção e assistência à saúde em geral, dentre as quais podemos citar o Plano de Prevenção de Riscos de Acidentes com Materiais Perfurocortantes.

A equipe de enfermagem está exposta, durante a assistência, a diversos riscos ocupacionais, sendo eles: químicos, físicos, mecânicos, biológicos, ergonômicos e psicossociais, que podem ocasionar doenças ocupacionais e acidentes de trabalho (MARZIALE; RODRIGUES, 2002).

Risco químico é o manuseio de gases e vapores e tem inteira relação com a área de atuação do trabalhador, tipo de produto químico e tempo de contato, além da concentração do produto. Risco físico refere-se à temperatura ambiental, a radiação ionizante, aos ruídos e iluminação em níveis inadequados e exposição do trabalhador a incêndios e choques elétricos (MARZIALE; RODRIGUES, 2002). 
Risco psicossocial é a sobrecarga devido ao contato direto com o sofrimento de pacientes, a dor e a morte, ritmo de trabalho, múltiplas tarefas, podendo ocasionar à depressão, insônia, drogas e fadiga mental; o risco mecânico são as lesões causadas pela manipulação de objetos cortantes, penetrantes e as quedas. Os agentes ergonômicos estão relacionados ao levantamento de peso para movimentação e transporte de pacientes e de equipamentos, a má postura, que pode causar problemas à saúde destes trabalhadores, como fraturas, lombalgias e varizes (MARZIALE; RODRIGUES, 2002).

Já o risco biológico, é o contato dos trabalhadores com microorganismos (vírus e/ou bactérias, principalmente) ou material infecto contagiante, que podem causar doenças como HIV, hepatite, herpes (MARZIALE; RODRIGUES, 2002).

As exposições dos trabalhadores a materiais biológicos contaminados constituem um risco aos profissionais da área da saúde, no seu local de trabalho. Apesar de estudos desenvolvidos nesta área, os acidentes que no qual envolvem sangue e outros fluídos orgânicos correspondem às exposições mais frequentemente

relatadas

(LARANJEIRAS, 2003).

$\mathrm{O}$ contato com microorganismos patológicos oriundo de acidentes ocasionados pela manipulação de material perfurocortante ocorre, com grande frequência, na execução do trabalho de enfermagem. A exposição ocupacional por material biológico é entendida como a possibilidade de contato com sangue e fluidos orgânicos no ambiente de trabalho, e as formas de exposição incluem inoculação percutânea, por intermédio de agulhas ou objetos cortantes, e o contato direto com pele e/ou mucosas. (MARZIALE; RODRIGUES, 2002, p. 572).

São os riscos biológicos que causam maior preocupação para os trabalhadores da saúde, por isso, é necessário programar medidas de biossegurança, as quais é uma ação educativa que tem como objetivo a preservação da saúde dos seres humanos, dos animais e do ambiente (PAULINO; LOPES; ROLIM, 2008).

Os trabalhadores da área de saúde têm como maior risco o acidente com material perfurocortante, no qual os profissionais ficam expostos a microorganismos patogênicos como a Hepatite $\mathrm{B}$, doença com maior incidência entre estes trabalhadores, Hepatite $\mathrm{C}$ e a 
Síndrome da Imunodeficiência Adquirida (AIDS) (MARZIALE; NISHIMURA; FERREIRA, 2004).

Contudo o interesse pela exposição ocupacional dos trabalhadores da saúde a patógenos sanguíneos é recente, com maior preocupação após o surgimento da epidemia da AIDS a partir dos anos 80 . Atualmente, o acidente de trabalho é uma emergência médica e se configura como um problema relevante entre os profissionais de saúde, em especial a exposição ocupacional a esses patógenos por meio de acidente com perfurocortante. (PAULINO; LOPES; ROLIM, 2008, p. 508).

Acidente de trabalho é aquele que advém do exercício do trabalho provocando lesão corporal e até a morte, perda ou diminuição (transitória ou permanente) da capacidade funcional. Pode ser típica quando ocorre dentro do local de trabalho ou como de trajeto quando ocorre na ida ou volta do trabalho (PAULINO; LOPES; ROLIM, 2008).

O hospital é o principal local de trabalho dos membros da equipe de enfermagem que, frequentemente, permanecem a maior parte de sua vida produtiva dentro desse ambiente, muitas vezes em mais de um turno de trabalho, devido aos baixos salários. Essa instituição, no qual se tenta salvar vidas $\mathrm{e}$ recuperar a saúde perdida das pessoas enfermas é a mesma que favorece o adoecer das pessoas que nela trabalham, porque, aparentemente não há preocupação com a proteção, promoção e manutenção da saúde de seus empregados. (XELEGATI; ROBAZZI, p. 351, 2003).

A agulha descartada de modo incorreto, bem como outros fatores relacionados a esses tipos de acidentes, pode acarretar impactos financeiros enormes, além de trazer implicações relativas às normas de assistência da instituição que presta serviços de saúde, uma vez que o funcionário acidentado deve ser acompanhado através da realização de exames específicos (Anti HIV, AgHbs, Anti HCV, Anti Hbs), além da possibilidade de usar medicações profiláticas para impedir a soroconversão do HIV (quimioprofilaxia), de acordo com a indicação e a gravidade do acidente. Dados de 2000 apontam que os custos gerados por um acidente com material perfurocortante entre a equipe de enfermagem pode variar de $\mathrm{R} \$ 800,00$ a $\mathrm{R} \$ 2.000,00$ por acidente (BOLICK, 2000).

Em estudo realizado no Brasil, com trabalhadores da saúde, visando à identificação do risco ocupacional 
de infecção pelo vírus da imunodeficiência humana, foi constatado que $88,8 \%$ dos acidentes de trabalhos notificados acometeram $\mathrm{o}$ pessoal $\mathrm{da}$ enfermagem. (MARIZALE; RODRIGUES, 2002, p. 573).

Com um grande contingente de trabalhadores de enfermagem em todo o país, que no qual desenvolvem atividades, algumas vezes, sem qualificação suficiente para realizar assistência com qualidade, com dupla jornada de trabalho para garantir o auto-sustento e de seus familiares, a falta de recursos para qualificação e tempo, cabem as instituições de saúde promover capacitações, a fim de que esses profissionais tenham acesso as técnicas e conhecimentos de biossegurança, que no qual irão permitir exercer funções de maneira segura e eficaz (AMARAL et al. 2005).

A exposição ocupacional aos patógenos pelo sangue tem como consequências não somente a infecção, mas também aos traumas psicológicos referentes pela espera de resultado de uma possível soroconversão e mudanças habituais como práticas sexuais, relacionamento social e familiar, efeitos das drogas profiláticas, entre outros (MARZIALE; RODRIGUES, 2002).
Alguns estudos nos mostram que ocorrem de uma a quatro soroconversões positivas por HIV a cada 1.000 punções acidentais e que a contaminação por vírus da Hepatite B por trabalhadores da saúde é bastante alta, devido à alta capacidade infectante (risco médio de infecção cerca de 3\%). Por vírus da Hepatite $\mathrm{C}$ é um pouco mais baixa, cerca de 1,8\% (SHIMIZU; RIBEIRO, 2002).

O Brasil ainda enfrenta o problema de subnotificação dos acidentes de trabalho na área da saúde, o que dificulta a análise da real situação. Alguns estudos mostram que a subnotificação tem relação com a falta de informação em relação aos riscos e aspectos epidemiológicos e jurídicos que envolvem o acidente, a submissão dos trabalhadores às condições impostas pelos serviços com relação à falta de tempo para notificação e o medo de perder emprego, principalmente nos setores privados. Também pode relacionar com a subnotificação a valoração da importância dada ao registro da Comunicação de Acidentes de Trabalho (CAT) dada pelos profissionais responsáveis por essa atividade, que no qual privilegiam cumprimentos de normas burocráticas, mas não o envolvimento profissional com a questão do acidentado, fazendo com que 
este fique sem motivação para notificar o acidente (SOUZA; CAMPOS, 2008).

De acordo com Souza e Campos (2008, p. 603) Um dos desafios da enfermagem consiste em consolidar prevenção, também, no ambiente de trabalho desenvolvendo ações educativas que minimizem a exposição a riscos de acidentes, atuando como profissionais comprometidos com a melhoria da saúde e o direito ao trabalho com dignidade e segurança para todos, o que implica em um envolvimento diferenciado com relação ao processo de trabalho em saúde, pois envolve questões de relacionamento humano no trabalho.

Segundo Vieira e Padilha (2008, p. 805) A adoção de técnicas e métodos adequados, bem como, a prática de medidas eficazes de higiene e segurança do trabalho eliminam ou minimizam os riscos ocupacionais. Tais medidas de prevenção e de controle de riscos biológicos se baseiam em conhecimentos diversos envolvendo sim, os de higiene e biossegurança do trabalho, assim como, de educação, administração, engenharia e até de recursos legislativos.

Para evitar os acidentes com perfurocortantes, há necessidade de não só promover periodicamente treinamentos nos serviços, com objetivo de diminuir a frequência dos acidentes, mas permitir que os trabalhadores consigam decodificar a organização do trabalho em que estão inseridos, podendo assim trabalhar com segurança e encontrando soluções para seu cotidiano (SARQUIS; FELLI, 2002).

Este artigo tem por objetivo trazer a reflexão o questionando do por que dos acidentes com materiais perfurocortantes ocorrer intensamente com os profissionais de enfermagem em seu exercício profissional.

Logo o este estudo deve identificar a ocorrência de acidentes com materiais perfurocortantes entre os profissionais de enfermagem e como a equipe de enfermagem pode atuar na prevenção destes acidentes.

Este estudo se fez relevante, pois durante o período como acadêmicos teve se a oportunidade de vivenciar situações em que o profissional da saúde não estava preparado ao realizar os procedimentos relativos ao uso dos perfurocortantes de forma adequada. Portanto, percebeu - se que muitas das vezes estes profissionais isoladamente e/ou juntamente com as suas equipes não possuem treinamentos adequados sobre as técnicas de manuseio dos materiais perfurocortantes. No entanto, não pode - se deixar de abordar também os 
diversos casos que ocorrem por causa dos profissionais que se encontram qualificados para a execução das técnicas, mas não dão a devida importância ao uso de equipamentos de proteção individual e consequentemente o número de pessoas acidentadas se torna significativamente alto e preocupante.

\section{MATERIAL E MÉTODOS}

Trata-se de uma pesquisa documental indireta, sendo descritivaexploratória, do tipo revisão bibliográfica integrativa, na busca de estudos literários nacionais sobre publicações relativas ao tema e exploratória junto a artigos publicados sobre o tema.

$$
\text { Uma revisão integrativa é um }
$$
método de revisão específica que resume a literatura teórica e empírica para oferecer uma maior compreensão de um fenômeno. A revisão integrativa tem o potencial de construir a ciência, informar as pesquisas, prática e iniciativas políticas. Ela bem feita contribui para o desenvolvimento da teoria, e tem aplicabilidade direta para prática e política. Whittemore e Knafl (2005).

Para a coleta de dados foi elaborado um instrumento com o objetivo de facilitar o processo de coleta e análise dos dados (APÊNDICE A).

Foram construídos quadros sinópticos relacionados aos autores das publicações, as características das publicações, a variável de interesse. A análise dos quadros foi realizada por meio da análise descritiva.

A população do estudo foi toda a literatura indexada nos bancos de dados selecionados, teses e dissertações relacionadas ao tema do estudo. A amostra foi realizada a partir da análise crítica da literatura, frente aos critérios de inclusão definidos nesse estudo.

A coleta de dados foi realizada nas bases de dados: Base de Dados de Enfermagem (BDENF), Biblioteca Virtual em Saúde (BVS), Biblioteca Regional de Medicina (BIREME), Literatura LatinoAmericana e do Caribe em Ciências da Saúde (LILACS), Literatura Internacional em Ciências da Saúde (MEDLINE), Scientific Eletronic Library Online (SCIELO), Manuais do Ministério da Saúde e das Secretarias Estaduais e Municipais e as Revistas Eletrônicas e como estratégia foi utilizado o formulário básico.

Foram utilizados os descritores de assunto "acidentes de trabalho" e 
"enfermagem" e pesquisados publicações no idioma português no período entre 2000 e 2011.A busca para composição da população do estudo foi iniciada através da base de dados LILACS utilizando o formulário básico como opção da pesquisa e descritores de assunto "acidentes de trabalho" e "enfermagem" e idioma português, encontrando assim 30 artigos, dos quais 07 foram selecionados para a amostra. Na base de dados MEDLINE foram utilizados os descritores "material biológico" e "enfermagem" e idioma português encontrando assim 08 artigos, e após análise da literatura, nenhuma amostra foi selecionada no MEDLINE.

$\mathrm{Na}$ base de dados SCIELO, a busca foi realizada através do BIREME, por meio do formulário básico e palavra chave "acidentes de trabalho" e "enfermagem". Dessa forma foram encontrados 09 artigos do qual 02 artigos fizeram parte da amostra.

De acordo com o quadro abaixo, a população do estudo ficou constituída por 47 artigos e após análise crítica da literatura considerando os critérios de inclusão e exclusão, a amostra ficou constituída por 09 artigos, pois foram excluídos os artigos internacionais, os que não estavam ligados diretamente ao tema e os que não estavam compreendidos entre o período de 2000 a 2011.

TABELA 1 - Base de dados da população e amostra

\begin{tabular}{lccc}
\hline Base de Dados & População & Amostra \\
\hline LILACS & 30 & 07 \\
SCIELO & 09 & 02 \\
TOTAL & 47 & 09 \\
& & \\
\hline
\end{tabular}

Fonte: Dados da pesquisa, 2011.

\section{RESULTADOS E DISCUSSÃO}

Após a leitura da amostra que constituíram este estudo, foram produzidos os resultados a partir dos quadros sinópticos que apresentam as sínteses dos autores, das publicações, da variável de estudo e caracterização da população de enfermagem, como exemplificado nos quadros a seguir: 
QUADRO 1 - Características dos autores das publicações que fizeram parte desta revisão.

\begin{tabular}{|c|c|c|c|c|}
\hline Literatura & Profissão & Área de atuação & País de Origem & Qualificação \\
\hline $\begin{array}{l}\text { 1)BARBOZA; } \\
\text { SOLER E } \\
\text { CIORLIA (2004). }\end{array}$ & $\begin{array}{l}2 \text { Enfermeiras do } \\
\text { Trabalho } \\
1 \text { Médico do } \\
\text { Trabalho }\end{array}$ & 3 Docentes & Não identificado & $\begin{array}{l}2 \text { Doutores } \\
1 \text { Mestre }\end{array}$ \\
\hline $\begin{array}{l}\text { 2) CANINI et al. } \\
\text { (2002). }\end{array}$ & $\begin{array}{l}2 \text { Enfermeiras } \\
1 \text { Enfermeira do } \\
\text { Trabalho }\end{array}$ & $\begin{array}{l}3 \text { Docentes } \\
1 \text { Não identificado }\end{array}$ & Não identificado & $\begin{array}{l}2 \text { Doutores } \\
2 \text { Graduados }\end{array}$ \\
\hline $\begin{array}{l}\text { 3) LIMA; } \\
\text { PINHEIRO E } \\
\text { VIEIRA (2007). }\end{array}$ & $\begin{array}{l}1 \text { Médica } \\
3 \text { Enfermeiras }\end{array}$ & $\begin{array}{l}2 \text { Docentes } \\
1 \text { Não identificado }\end{array}$ & Não identificado & $\begin{array}{l}1 \text { Especialista } \\
2 \text { Graduação }\end{array}$ \\
\hline $\begin{array}{l}\text { 4) MARZIALE; } \\
\text { NISHIMURA E } \\
\text { FERREIRA (2004) }\end{array}$ & $\begin{array}{l}1 \text { Enfermeira } \\
2 \text { Discentes }\end{array}$ & $\begin{array}{l}1 \text { Docente } \\
2 \text { Bolsistas IC - } \\
\text { CNPQ }\end{array}$ & Não identificado & $\begin{array}{l}1 \text { Graduação } \\
2 \text { Graduandos }\end{array}$ \\
\hline $\begin{array}{l}\text { 5) MARZIALE E } \\
\text { RODRIGUES } \\
(2002) .\end{array}$ & 2 Enfermeiras & $\begin{array}{l}1 \text { Docente } \\
1 \text { Bolsista IC - } \\
\text { CNPQ }\end{array}$ & Não identificado & 2 Graduação \\
\hline $\begin{array}{l}\text { 6) PAULINO E } \\
\text { LOPES; } \\
\text { ROLIM (2008). }\end{array}$ & 3 Enfermeiras & $\begin{array}{l}2 \text { Docentes } \\
1 \text { Não identificado }\end{array}$ & Não identificado & $\begin{array}{l}1 \text { Doutor } \\
1 \text { Especialista } \\
1 \text { Graduação }\end{array}$ \\
\hline $\begin{array}{l}\text { 7) SARQUIS E } \\
\text { FELLI (2002). }\end{array}$ & 2 Enfermeiras & 2 Docentes & Não identificado & 2 Graduação \\
\hline $\begin{array}{l}\text { 8) SHIMIZU E } \\
\text { RIBEIRO (2002). }\end{array}$ & 2 Enfermeiras & $\begin{array}{l}1 \text { Docente } \\
1 \text { Não identificado }\end{array}$ & Não identificado & $\begin{array}{l}1 \text { Doutora } \\
1 \text { Especialista }\end{array}$ \\
\hline $\begin{array}{l}\text { 9) TOMAZIN E } \\
\text { BENATTI (2001) }\end{array}$ & $\begin{array}{l}1 \text { Enfermeira } \\
1 \text { Enfermeira do } \\
\text { trabalho }\end{array}$ & $\begin{array}{l}1 \text { Docente } \\
1 \text { Não identificado }\end{array}$ & Não identificado & $\begin{array}{l}1 \text { Graduado } \\
1 \text { Docente }\end{array}$ \\
\hline
\end{tabular}

Fonte: Dados da pesquisa, 2011. 
Quanto à autoria das 09 publicações, constatou-se 24 autores, sendo que $66,6 \%$ são enfermeiros, $16,7 \%$ são enfermeiros do trabalho, $8,3 \%$ são discentes, 4,2\% são médicos do trabalho e 4,2\% são médicos. Em relação à área de atuação dos autores, foi possível identificar que $66,7 \%$ atuam na Docência, $20,8 \%$ não foram identificados e $12,5 \%$ são bolsistas. Quanto ao país de origem, $100 \%$ dos autores não informam a nacionalidade. Segundo a qualificação dos autores, 54,2\% tem a graduação, 29,2\% são doutores, $12,5 \%$ tem especialização e $4,2 \%$ são mestres.

QUADRO 2 - Características das publicações que fizeram parte dessa revisão

\begin{tabular}{|c|c|c|c|c|c|}
\hline Literatura & Periódico & $\begin{array}{c}\text { Ano de } \\
\text { Publicação }\end{array}$ & Fonte & Delineamento & Tipo de publicação \\
\hline $\begin{array}{l}\text { 1)BARBOZA; } \\
\text { SOLER E } \\
\text { CIORLIA }\end{array}$ & $\begin{array}{l}\text { Arquivo Ciência } \\
\text { Saúde }\end{array}$ & 2004 & Lilacs & $\begin{array}{l}\text { Estudo } \\
\text { epidemiológico } \\
\text { retrospectivo }\end{array}$ & Artigo \\
\hline
\end{tabular}

(2004).

\begin{tabular}{lllll}
\hline 2) CANINI et al. & Revista Latino- & 2002 & Lilacs & Estudo descritivo \\
(2002). & Americana de & & & retrospectivo \\
& Enfermagem & & &
\end{tabular}

\begin{tabular}{|c|c|c|c|c|c|}
\hline $\begin{array}{l}\text { 3) LIMA; } \\
\text { PINHEIRO E } \\
\text { VIEIRA (2007). }\end{array}$ & $\begin{array}{l}\text { Revista de } \\
\text { Enfermagem }\end{array}$ & 2007 & Lilacs & $\begin{array}{l}\text { Pesquisa descritiva } \\
\text { qualitativa }\end{array}$ & Artigo \\
\hline $\begin{array}{l}\text { 4) MARZIALE; } \\
\text { NISHIMURA E } \\
\text { FERREIRA } \\
\text { (2004). }\end{array}$ & $\begin{array}{l}\text { Revista Latino- } \\
\text { Americana de } \\
\text { Enfermagem }\end{array}$ & 2004 & Lilacs & $\begin{array}{l}\text { Pesquisa descritiva } \\
\text { quantitativa }\end{array}$ & Artigo \\
\hline $\begin{array}{l}\text { 5) MARZIALE E } \\
\text { RODRIGUES } \\
(2002) .\end{array}$ & $\begin{array}{l}\text { Revista Latino- } \\
\text { Americana de } \\
\text { Enfermagem }\end{array}$ & 2002 & Lilacs & $\begin{array}{l}\text { Levantamento } \\
\text { bibliográfico }\end{array}$ & Artigo \\
\hline $\begin{array}{l}\text { 6) PAULINO; } \\
\text { LOPES E } \\
\text { ROLIM (2008). }\end{array}$ & $\begin{array}{l}\text { Cogitare } \\
\text { Enfermagem }\end{array}$ & 2008 & Lilacs & $\begin{array}{l}\text { Estudo documental } \\
\text { exploratório }\end{array}$ & Artigo \\
\hline $\begin{array}{l}\text { 7) SARQUIS E } \\
\text { FELLI (2002). }\end{array}$ & $\begin{array}{l}\text { Revista Escola } \\
\text { de Enfermagem }\end{array}$ & 2002 & Scielo & $\begin{array}{l}\text { Estudo descritivo } \\
\text { exploratório }\end{array}$ & Artigo \\
\hline
\end{tabular}




\begin{tabular}{lllll}
\hline 8) SHIMIZU E & Revista Escola & 2002 & Lilacs & $\begin{array}{l}\text { Estudo descritivo } \\
\text { exploratório }\end{array}$
\end{tabular}

\begin{tabular}{|c|c|c|c|c|c|}
\hline $\begin{array}{l}\text { 9) TOMAZIN E } \\
\text { BENATTI } \\
(2001)\end{array}$ & $\begin{array}{l}\text { Revista Gaúcha } \\
\text { de Enfermagem }\end{array}$ & 2001 & Bireme & $\begin{array}{l}\text { Estudo } \\
\text { exploratório } \\
\text { descritivo }\end{array}$ & Artigo \\
\hline
\end{tabular}

Fonte: Dados da pesquisa, 2011.

Quanto aos tipos de revistas analisarmos os delineamentos de pesquisa científicas que fizeram parte dessa revisão, dos artigos incluídos, foram constatados 33,4\% foram extraídos da Revista Latino- $\quad$ que 33,4\% é estudo descritivo exploratório, Americana de Enfermagem, 22,2\% da $11,1 \%$ é estudo epidemiológico Revista Escola de Enfermagem, $11,1 \%$ da retrospectivo, $11,1 \%$ é estudo descritivo Cogitare Enfermagem, 11,1\% do Arquivo retrospectivo, $11,1 \%$ pesquisa descritiva Ciência e Saúde, $11,1 \%$ da Revista de qualitativa, $11,1 \%$ pesquisa descritiva Enfermagem e $11,1 \%$ da Revista Gaúcha quantitativa, 11,1\% levantamento de Enfermagem. Em relação ao ano de bibliográfico e 11,1\% é estudo documental publicação, 44,5\% foram publicados em exploratório. Quanto ao tipo de publicação, 2002, 22,2\% foram publicados em 2004, $11,1 \%$ em 2008, 11,1\% foram publicados em 2007 e 11,1\% foram publicados em 2001. Das fontes de buscas utilizadas, $77,8 \%$ foram extraídas da base de dados LILACS e $11,1 \%$ da base de dados SCIELO e $11,11 \%$ do BIREME. Ao $100 \%$ foram artigos.

A partir da leitura e análise dos artigos, foi construído o quadro sinóptico com as sínteses das publicações que fizeram parte deste estudo, conforme quadro abaixo.

QUADRO 3 -Acidentes com materiais perfurocortantes e o profissional de enfermagem.

\begin{tabular}{l|l}
\hline \multicolumn{1}{c}{ Literatura } & \multicolumn{1}{c}{ Acidentes com materiais perfurocortantes e o profissional de enfermagem. } \\
\hline & $\begin{array}{l}\text { Maiorias dos trabalhadores acometidos por acidentes com perfurocortantes eram do } \\
\text { sexo feminino, pertenciam à categoria auxiliar de enfermagem; }\end{array}$ \\
1)BARBOZA; SOLER E & $\begin{array}{l}\text { Mais ocorrências de acidentes com perfurocortantes entre trabalhadores de } \\
\text { enfermagem que atuavam em unidade especializada, principalmente Centro- } \\
\text { CIORLIA (2004). }\end{array}$ \\
& Cirúrgico, seguida de Pronto Socorro e Hematologia; \\
& As agulhas são materiais causadores principais e o dedo é a região do corpo mais \\
\hline
\end{tabular}


atingida;

Necessidade programas de orientação e reciclagem entre a equipe de enfermagem.

Maior ocorrência entre auxiliares de enfermagem, seguida dos funcionários da limpeza;

A maioria dos acidentes são ocasionados por agulhas e outros objetos perfurocortantes;

2) CANINI et al. (2002). enfermagem e os que mais estão em contato direto com o paciente, portanto sofrendo maior exposição a esse tipo de risco;

Maioria dos acidentes ocorreu quando trabalhadores de enfermagem estavam administrando medicamentos;

Necessidade de treinamento entre a equipe de enfermagem.

A rapidez em razão do número acentuado de clientes e intercorrências facilitam ocorrência de acidentes;

Predispõe a ocorrência à administração de medicamentos e o contato com material

3) LIMA; PINHEIRO E perfurocortante;

VIEIRA (2007).

Necessidade de mais um emprego aumenta o tempo de exposição ao risco;

Falta de capacitação dos profissionais.

Maior incidência em trabalhadores do sexo feminino;

4)MARZIALE;

Maior número de acidentes com agulhas e durante administração de medicamentos;

NISHIMURA E

Medidas preventivas precisam ser revistas.

FERREIRA (2004).

Categoria mais acometida é dos auxiliares de enfermagem;

5) MARZIALE E

Principal fator é o reencape de agulhas;

RODRIGUES (2002).

Falta de educação continuada estão associados à ocorrência dos acidentes.

Maior número com auxiliares de enfermagem;

A ocasião em que mais aconteceram os acidentes foi ao reencapar agulhas;

6) PAULINO; LOPES E

Agulhas de seringa foram os objetos que mais causaram acidentes;

ROLIM (2008).

As partes do corpo mais atingidas foram os membros superiores (mãos e dedos).

7) SARQUIS E FELLI

(2002).

8) TOMAZIN E BENATTI Maioria dos acidentes causados dentro da faixa etária de 20 a 29 anos;

(2001).

Prevalência em mulheres.
Categoria de auxiliares de enfermagem foi a que mais sofreu acidente de trabalho;

Frequencia é maior entre as mulheres;

Objeto mais causador é o perfurocortante (agulhas de injeção).

Pessoal do serviço de higienização tem sofrido acidentes devido a descuidos;

9) SHIMIZU E RIBEIRO (2002).
Maior número de acidentes ocorreu nas clínicas médicas, maternidade/centro obstétrico e clínica cirúrgica;

Maioria dos acidentes é causada por agulhas, devido a pratica do reencape. 
$\mathrm{Na}$ análise da literatura, encontramos pontos que são em comuns na maioria dos autores, com pequenos pontos convergentes.

De acordo com todos os autores, a categoria de profissionais que mais se acidentam são os auxiliares de enfermagem, pois, são profissionais que tem maior contato com o paciente e, portanto os que mais sofrem exposição a esse tipo de risco. Canini et al. (2002) afirma que após os auxiliares de enfermagem, a categoria profissional que mais se acidenta é a dos serviços gerais, devido ao descarte incorreto do perfurocortante. Todos os autores afirmam que a frequência é maior entre as mulheres, pois, há predominância de maior público feminino nos hospitais.

Todos os autores citados também afirmam que as agulhas são os principais causadores de acidentes, principalmente devido ao reencape de agulhas que ocorrem durante a administração de medicamentos.

Autores como Barboza; Soler e Ciorlia (2004) afirmam que ocorrem mais acidentes com perfurocortantes entre trabalhadores de enfermagem que atuam em unidades especializadas, principalmente nos Centros-Cirúrgicos, seguida de Pronto Socorro e Hematologia. Já Shimizu e Ribeiro (2002) afirmam que os acidentes ocorrem em maior número em Clínica Médica, Maternidade/Centro Obstétrico e Clínica Cirúrgica.

Muitos autores enfatizam que há necessidade de intervenções por parte dos enfermeiros, no que diz respeito a medidas preventivas e programas de educação continuada, abordando a questão dos acidentes e a exposição a material biológico.

Barboza; Soler e Ciorlia (2004) e Paulino; Lopes e Rolim (2008) apontam que as partes dos corpos mais atingidas por perfurocortantes são os membros superiores (mãos e dedos), devido à maior manipulação dessas aéreas na execução de tarefas.

A tabela a seguir descreve os achados de BARBOZA, SOLER e CIORLIA (2004) quanto ao sexo, faixa etária e estado civil dos profissionais de enfermagem envolvidos em acidentes correlacionando-os com a categoria de cada profissional. 
TABELA 2 - Caracterização da população profissional de enfermagem.

\begin{tabular}{|c|c|c|c|c|c|c|c|c|}
\hline \multirow[t]{2}{*}{ CARACTERÍSTICAS } & \multicolumn{2}{|c|}{ ENFERMEIRO } & \multicolumn{2}{|c|}{ AUXILIAR } & \multicolumn{2}{|c|}{ ATENDENTE } & \multicolumn{2}{|c|}{ TOTAL } \\
\hline & N. ${ }^{\circ}$ & $\%$ & N. ${ }^{\circ}$ & $\%$ & N. ${ }^{\circ}$ & $\%$ & N. ${ }^{o}$ & $\%$ \\
\hline \multicolumn{9}{|l|}{ Sexo } \\
\hline Masculino & 01 & 0,4 & 44 & 16,2 & 09 & 3,3 & 54 & 19,9 \\
\hline Feminino & 15 & 5,5 & 164 & 60,3 & 39 & 14,3 & 218 & 80,1 \\
\hline Total & 16 & 5,9 & 208 & 76,5 & 48 & 17,6 & 272 & 100,0 \\
\hline \multicolumn{9}{|l|}{ Faixa Etária (em anos) } \\
\hline 20 a 29 & 09 & 3,3 & 75 & 27,6 & 09 & 3,3 & 93 & 34,2 \\
\hline 30 a 39 & 05 & 1,8 & 92 & 33,8 & 13 & 4,8 & 110 & 40,4 \\
\hline 40 a 49 & 02 & 0,7 & 31 & 11,4 & 20 & 7,4 & 53 & 19,5 \\
\hline \multicolumn{9}{|l|}{50 a 59} \\
\hline 60 em diante & - & - & 01 & 0,4 & - & - & 01 & 0,4 \\
\hline Total & 16 & 5,9 & 208 & 76,5 & 48 & 17,6 & 272 & 100,0 \\
\hline \multicolumn{9}{|l|}{ Estado Civil } \\
\hline Solteiro & 07 & 2,6 & 98 & 36,0 & 16 & 5,9 & 121 & 44,5 \\
\hline Casado & 08 & 2,9 & 93 & 34,2 & 26 & 9,6 & 127 & 46,7 \\
\hline Outro & 01 & 0,4 & 17 & 6,3 & 06 & 2,2 & 24 & 8,8 \\
\hline Total & 16 & 5,9 & 208 & 76,5 & 48 & 17,7 & 272 & 100,0 \\
\hline
\end{tabular}

Ainda segundo os autores, ocorreram 272 acidentes acometendo 16 $(5,9 \%)$ enfermeiros, $208(76,5 \%)$ auxiliares de enfermagem e 48(17,6\%) atendentes de enfermagem. A Tab. 1 traz a caracterização da população quanto ao sexo, faixa etária e estado civil, segundo a categoria profissional, onde se verifica que

\section{CONCLUSÕES}

Após uma leitura crítica da literatura, constatou - se que os acidentes a maioria dos trabalhadores acometidos por acidentes com perfurocortantes eram do sexo feminino $218(80,1 \%)$, pertenciam à categoria de auxiliar de enfermagem 208 $(76,5 \%)$, tinham entre 20 a 39 anos 203 $(74,6 \%)$ e eram casados $151(55,5 \%)$ ou tinham união consensual (BARBOZA; SOLER E CIORLIA, 2004).

com materiais perfurocortantes ocorrem com maior intensidade com as categorias de auxiliares de enfermagem, devido à maior manipulação com os pacientes e os procedimentos realizados. 
Verificou-se, que o sexo feminino é o mais acometido devido a um maior número de mulheres que estão presentes na área hospitalar. Em relação ao objeto causador dos acidentes, identificou-se que as agulhas foram as responsáveis pelo maior número de acidentes, devido a alguns hábitos do cotidiano de trabalho que resultam na exposição frequente aos acidentes com materiais biológicos, como o reencape de agulhas.

Os dados obtidos neste estudo revelam aspectos importantes dos riscos a que estão expostos os trabalhadores de enfermagem na manipulação de materiais perfurocortantes, oferecendo condições para que sejam implementadas programas de orientação e capacitação da equipe de enfermagem. $\mathrm{O}$ sucesso de qualquer programa educativo está diretamente ligado à participação e ao reconhecimento por parte dos trabalhadores e o apoio da instituição.

Então, é importante que o enfermeiro execute programas de educação continuada nos hospitais, e que aborde mais a questão dos acidentes de trabalho e a exposição aos materiais perfurocortantes, esclarecendo bem aos profissionais de enfermagem sobre a importância de se notificar o ocorrido, a busca pelo atendimento médico nos primeiros momentos que seguem o acidente, sensibilizá-los quanto à utilização correta dos EPI e a precauções padrões.

Ao final deste trabalho acredita - se ter demonstrado quais os profissionais de enfermagem que estão expostos aos acidentes e sendo este tema de suma importância para profissionais de saúde para providenciarem medidas preventivas em pró da saúde do trabalhador. Após a busca da literatura nos bancos de dados online observou que a literatura científica sobre este tema ainda é escassa, por isso há necessidade de pesquisas como contribuintes para o aprimoramento/aprofundamento de conhecimentos na área. Espera - se, com isso ter estimulado o interesse para outros estudos.

\section{REFERENCIAS}

AMARAL, S. A. et al. Acidentes com materiais perfurocortante entre profissionais de saúde em hospital privado de Vitória da Conquista - BA.

Sittientibus, Feira de Santana, n. 33, p. 101-114, jul./dez. 2005.

BARBOZA, D. B.; SOLER, Z. A. S. G.; CIORLIA, L. A. S. Acidentes de trabalho com perfurocortante envolvendo a equipe 
de enfermagem de um hospital de ensino. Arquivo Ciência em Saúde, v. 11, n. 2, p. 1-8, 2004.

BRASIL. Ministério do Trabalho e Emprego. Disponível em: < http://www.mte.gov.br/seg_sau/guia tecni co_cs3.pdf $>$. Acesso em: 26 out 2011.

BRASIL. Ministério do trabalho e Emprego. Disponível em: < http://portal.mte.gov.br/data/files/8A7C812 D3226A41101323B5152AF4497/nr_32.pd f>. Acesso em 26 out 2011.

BOLICK, D. et al. Segurança e controle de infecção. Rio de Janeiro: Reuchmanne \& Affonso Editores, 2000.

CANINI, S. R. M. S. et al. Acidentes perfurocortantes entre trabalhadores de enfermagem de um hospital universitário do interior paulista. Revista Latino Americana de Enfermagem. Ribeirão Preto, v. 10, n. 2, p. 172-178, mar./abr. 2002.

\section{LARANJEIRAS, L. Objetos}

Perfurocortantes. In: Cola da Web, 2003. Disponível em < http://www.coladaweb.com/medicina-eenfermagem/objetos-perfurocortantes $>$. Acesso em: 26 out 2011.

LIMA, F. A.; PINHEIRO, P. N. C.; VIEIRA, N. F. C. Acidentes com material perfurocortante: conhecendo os sentimentos e as emoções dos profissionais de enfermagem. Escola Anna Nery Revista de Enfermagem, v. 11, n. 2, p. 205-211, jun. 2007.
MARZIALE, M. H. P.; NISHIMURA, K. Y. N.; FERREIRA, M. M. Riscos de contaminação ocasionados por acidentes de trabalho com materiais perfurocortante entre trabalhadores de enfermagem.

Revista Latino-Americana de Enfermagem, Ribeirão Preto, v. 12, n. 1, p. 36-42, jan/fev. 2004.

MARZIALE, M. H. P.; RODRIGUES, C. M. A produção científica sobre os acidentes de trabalho com material perfurocortante entre trabalhadores de enfermagem. Revista Latino- Americana de Enfermagem, Ribeirão Preto, v. 10, n. 4, p. 571-577, jul/ago. 2002.

PAULINO, D. C. R.; LOPES, M. V. O.; ROLIM, I. L. T. P. Biossegurança e acidentes de trabalho com perfurocortantes entre os profissionais de enfermagem de hospital universitário de Fortaleza-CE. Cogitare Enfermagem, v. 13, n. 4, p. 507513, out/dez. 2008.

SANTANA, V. S. et al. Acidentes de trabalho: custos previdenciários e dias de trabalho perdido. Revista de Saúde Pública, v. 40, n. 6, p. 1004-1012, 2006.

SARQUIS, L. M. M.; FELLI, V. E. A. Acidentes de trabalho com instrumentos perfurocortantes entre os trabalhadores de enfermagem. Revista Escola de Enfermagem da USP, São Paulo, v. 36, n. 3, p. 222-230, 2002.

SHIMIZU, H. E.; RIBEIRO, E. J. G. Ocorrência de acidente de trabalho por materiais perfurocortantes e fluidos biológicos em estudantes e trabalhadores 
da saúde de um hospital escolha de Brasília. Revista Escola de Enfermagem da USP, São Paulo, v. 26, n. 4, p. 367375, 2002.

SOUZA, J. V.; CAMPOS, L. F. Relato de experiência quanto à orientação de conduta frente a acidentes de trabalho com perfurocortantes e fluidos orgânicos.

Cogitare Enfermagem, v. 13, n. 4, p. 602-606, out/dez. 2008.

TOMAZIN, C. C; BENATTI, M. C.C. Acidente do Trabalho por material perfurocortante em trabalhadores de enfermagem. Revista Gaúcha de Enfermagem, Porto Alegre, v. 22, n. 2, p. 60-73, jul. 2001.
VIEIRA, M; PADILHA, M.I.C.S. O HIV e o trabalhador de enfermagem frente ao acidente com material perfurocortante. Revista Escola de Enfermagem da USP, São Paulo, v. 42, n. 4, p. 805, 2008.

WHITTEMORE, R; KNAFL, K. Uma revisão integrativa: uma metodologia atualizada. Journal of Advanced Nursing, Oregon, v. 52, n. 5, p. 546-553, 2005.

XELEGATI, R.; ROBAZZI, M. L. C. C. Riscos químicos a que estão submetidos os trabalhadores de enfermagem: uma revisão de literatura. Revista Latino-Americana de Enfermagem, v. 11, n. 3, p. 350-356, maio/jun. 2003.

\section{APENDICE A - Formulário de Coleta de Dados}

\begin{tabular}{|l|l|l|l|}
\hline Autor & Publicação \\
\hline Profissão: & Periódico: & \\
\hline Área de Atuação: & Ano de Publicação: & \\
\hline País de Origem: & Fonte: & \\
\hline Qualificação: & Delineamento: & \\
\cline { 3 - 4 } & Tipo de Publicação: & $\begin{array}{l}\text { Acidentes com materiais } \\
\text { perfurocortantes e o } \\
\text { profissional de enfermagem. }\end{array}$ \\
\cline { 3 - 4 } & Variável de Interesse: & \\
\hline & & \\
\hline
\end{tabular}

